\title{
Article
}

\section{The Norwegian Twin Registry}

\author{
Thomas Nilsen ${ }^{1}$, Ingunn Brandt ${ }^{1}$ and Jennifer R. Harris ${ }^{2}$ \\ ${ }^{1}$ Department of Health Studies, Division for Health Data and Digitalization, The Norwegian Institute of Public Health, Oslo, Norway and ${ }^{2}$ Division for Health Data \\ and Digitalization, The Norwegian Institute of Public Health, Oslo, Norway
}

\begin{abstract}
The Norwegian Twin Registry (NTR) is maintained as a research resource that was compiled by merging several panels of twin data that were established for research into physical and mental health, wellbeing and development. NTR is a consent-based registry. Where possible, data that were collected in previous studies are curated for secondary research use. A particularly valuable potential benefit associated with the Norwegian twin data lies in the opportunities to expand and enhance the data through record linkage to nationwide registries that cover a wide array of health data and other information, including socioeconomic factors. This article provides a brief description of the current NTR sample and data collections, information about data access procedures and an overview of the national registries that can be linked to the NTR for research projects.
\end{abstract}

Keywords: Health registries; Norway; Norwegian Twin Registry; NTR; twins

(Received 4 July 2019; accepted 5 July 2019; First Published online 10 September 2019)

Twin research has a long tradition in Norway, starting in the 1960s with research into psychosis (Kringlen, 2016). Several twin panels were subsequently set up in the following decades (Bergem, 2002; Harris et al., 2002, 1995; Magnus et al., 2016). In 2009, the Norwegian Twin Registry (NTR) was established to create a single resource of Norwegian twin data from these previous studies, and it integrated data collections that had been conducted at several institutions in Norway (Magnus et al., 2016; Nilsen et al., 2012, 2013). Due to legal reasons, primarily related to the lack of current consents, data from most of the earliest studies had to be deleted because respective data use permissions had expired.

Today, the NTR is a consent-based health registry; the twins have consented to participate and have agreed that the information that has been collected from them can be maintained in the NTR. For this reason, the sample size for the full NTR fluctuates because pairs who participated in original studies may have decided not to continue their participation in the NTR. New substudies can be initiated and in cases where this entails new data collections then a new consent must be obtained. The NTR is maintained by the Division for Health Data and Digitalization at the Norwegian Institute of Public Health (NIPH) in Oslo. This article provides a brief description of NTR and its contents.

\section{Description of the NTR Sample and Data Collections}

Table 1 provides an overview of the current number of twin-pairs and individuals in the NTR by zygosity and sex and across birth years.

The NTR does not have dedicated funding for data collection. Most of the data were collected through various substudies or

\footnotetext{
Author for correspondence: Jennifer R. Harris, Email: Jennifer.Harris@fhi.no Cite this article: Nilsen T, Brandt I, and Harris JR. (2019) The Norwegian Twin Registry. Twin Research and Human Genetics 22: 647-650, https://doi.org/10.1017/thg.2019.59
}

through the establishment of twin cohort programs of research that have now been integrated to constitute the NTR. Therefore, only a limited set of variables or measures are available across the whole registry. Most of the NTR data derive from self-reports based on questionnaire studies or from interviews. Table 2 provides a brief overview of studies and data collections contributing to the NTR. Here, it is important to note that the sample sizes in the table do not reflect the original sample sizes for the respective data collections because twins have opted out then. Zygosity was determined by questionnaire methods inquiring about twin similarity and has been verified in subsamples by genetic markers in blood, serum and red cell enzyme systems, and later by DNA analysis (Magnus et al., 1983; Nilsen et al., 2012; Tambs et al., 1995).

For twins born from 1967 onwards, the NTR also has data from the Medical Birth Registry of Norway (Irgens, 2002), including birth weight, birth order and other information that is routinely collected at birth including information about the delivery, the newborn, congenital diseases/malformations, birth weight/length, gestational age, Apgar scores, injuries and illnesses at birth. For twins born before 1967, information about birth is based on self-reported birth weight, gestational age, caesarean or regular birth, birth order and congenital diseases.

\section{Record Linkage Between the NTR and Other National Registers}

A particularly valuable potential associated with the Norwegian twin data lies in the record linkage opportunities offered by the many nationwide registries covering a wide array of health data and other information including socioeconomic factors. All Norwegians are assigned a personal identification number (PID) at birth. PID is also assigned to immigrants when obtaining legal

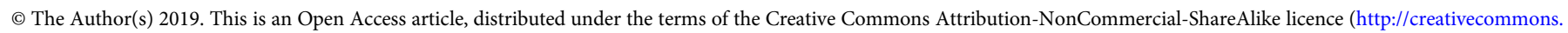

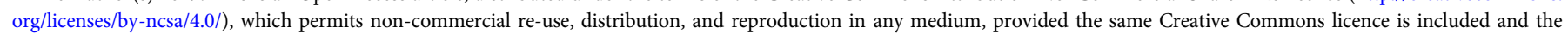
original work is properly cited. The written permission of Cambridge University Press must be obtained for commercial re-use. 
Table 1. Overview of current sample size in the NTR by birth cohort and zygosity

\begin{tabular}{|c|c|c|c|c|c|c|c|}
\hline \multirow[b]{2}{*}{ Birth cohort } & \multicolumn{5}{|c|}{ Number of complete pairs ${ }^{a}$} & \multirow[b]{2}{*}{ Total pairs } & \multirow[b]{2}{*}{ Total individuals } \\
\hline & MZM & $\mathrm{MZF}$ & DZM & DZF & $\mathrm{DZU}$ & & \\
\hline 1915-1924 & 195 & 279 & 318 & 383 & 1 & 1176 & 3053 \\
\hline $1925-1934$ & 258 & 319 & 377 & 441 & 1 & 1396 & 3347 \\
\hline 1935-1944 & 390 & 428 & 476 & 518 & 0 & 1812 & 4159 \\
\hline 1945-1954 & 570 & 651 & 838 & 919 & 0 & 2978 & 6589 \\
\hline $1955-1960$ & 342 & 417 & 538 & 539 & 1 & 1837 & 3959 \\
\hline $1967-1974$ & 263 & 405 & 196 & 291 & 432 & 1587 & 4479 \\
\hline $1975-1984$ & 265 & 417 & 120 & 253 & 301 & 1356 & 3883 \\
\hline $1985-1991$ & 157 & 329 & 98 & 224 & 275 & 1083 & 3195 \\
\hline Total & 2440 & 3245 & 2961 & 3568 & 1011 & 13,225 & 32,664 \\
\hline
\end{tabular}

Note: $\mathrm{MZM}=$ monozygotic male; $\mathrm{MZF}=$ monozygotic female; $\mathrm{DZM}=$ dizygotic male; $\mathrm{DZF}=$ dizygotic female; $\mathrm{DZU}=$ dizygotic unlike-sex

ancludes pairs where zygosity classification is based on responses from a single rater/twin.

Includes single twins.

Table 2. Data collections comprising the NTR and respective sample sizes stratified by zygosity

\begin{tabular}{|c|c|c|c|c|}
\hline \multirow{2}{*}{$\begin{array}{l}\text { Data collections (studies) } \\
\text { D1. Recruitment/zygosity determination } \\
\text { (Bergem, 2002; Magnus et al., 2016; } \\
\text { Nilsen et al., 2012) }\end{array}$} & \multirow{2}{*}{$\begin{array}{l}\text { Contents } \\
\text { Twin similarity: physical features and interests }\end{array}$} & \multirow{2}{*}{$\frac{\text { Cohort }}{1915-1960}$} & \multicolumn{2}{|c|}{$\begin{array}{l}\text { Pairs currently in } \\
\text { NTR }^{\mathrm{a}} \text { MZ DZ (DZU) }\end{array}$} \\
\hline & & & 3849 & 5347 (3) \\
\hline $\begin{array}{l}\text { D2. (1980) Congenital disease, general } \\
\text { health and health behavior (Bergem, 2002; } \\
\text { Nilsen et al., 2012) }\end{array}$ & $\begin{array}{l}\text { Health behavior: smoking, alcohol and physical activity } \\
\text { General health: general screening for somatic and congenital } \\
\text { disease } \\
\text { Self-rated health, twin similarity and contact with co-twin }\end{array}$ & $1915-1960$ & 2408 & 2755 (1) \\
\hline $\begin{array}{l}\text { D4. 1992: Follow up of D2 (Bergem, 2002; } \\
\text { Magnus et al., 2016; Nilsen et al., 2012) }\end{array}$ & $\begin{array}{l}\text { Follow up to D2: female conditions, for example, menstrual } \\
\text { pains. Depression and anxiety. Diet }\end{array}$ & $1915-1960$ & 1041 & 1128 \\
\hline $\begin{array}{l}\text { D7. } 1998 \text { Follow up D6 and recruitment of } \\
\text { new cohorts (Harris et al., 2006) }\end{array}$ & $\begin{array}{l}\text { Repeated questions from D6. In addition: expansion of physical } \\
\text { health and health behavior measures. Mental health: Axis II } \\
\text { disorders (DSM III-R) and short version of SCL-25 }\end{array}$ & $1967-1979$ & 861 & 1069 (489) \\
\hline $\begin{array}{l}\text { D8. 1999-2004 Mental health interview } \\
\text { (Nilsen et al., 2013) }\end{array}$ & $\begin{array}{l}\text { Interview data. Lifetime history of psychiatric disorders, } \\
\text { including substance abuse (Axis I), and personality disorders } \\
\text { (Axis II) Norwegian version of the Munich-Composite } \\
\text { International Diagnostic Interview and Norwegian version of the } \\
\text { Structured Interview for DSM-IV Personality }\end{array}$ & $1967-1979$ & 533 & $527(241)$ \\
\hline $\begin{array}{l}\text { D9. } 2011 \text { Chronic pain, personality and } \\
\text { quality of life (Roysamb et al., 2018; } \\
\text { Vassend et al., 2011) }\end{array}$ & $\begin{array}{l}\text { NEO-PI-R ( } 240 \text { items), Health behavior, physical health, pain } \\
\text { and bodily afflictions, wellbeing, HSCL and dental anxiety }\end{array}$ & $1945-1960$ & 327 & 309 \\
\hline
\end{tabular}

Note: $\mathrm{HSCL}=$ hopkins symptom checklist; NEO-PI-R = the revised neuroticism, extraversion, openness - personality inventory; MZ = monozygotic; DZ = dizygotic; DZU = dizygotic unlike-sex. a Sample sizes listed in this table reflect the number of pairs currently in the NTR and are smaller than the number of pairs participating in the original studies or data collections.

bFemale twins only.

'Twin family study where either the twin or their spouse may have responded. 
Table 3. Overview of main nationwide registries from which data may be linked to NTR for research studies

\begin{tabular}{|c|c|c|}
\hline Registry & Coverage from year & Contents \\
\hline Cancer Registry & 1952 & Incidence/diagnosis/mortality Clinical registries for specific cancers \\
\hline Medical Birth Registry Norway & 1967 & $\begin{array}{l}\text { Births/stillbirths, complications/newborn health, maternal health before and during } \\
\text { pregnancy }\end{array}$ \\
\hline Causes of Death Registry & 1925 (1951 electronic form) & Cause of death \\
\hline Norwegian Immunization Registry & 1995 & $\begin{array}{l}\text { Individual vaccination status/monitor vaccination coverage in the Norwegian } \\
\text { population }\end{array}$ \\
\hline Norwegian Prescription Database & 2004 & $\begin{array}{l}\text { Overview about dispensing of prescribed medicines to patients, doctors and } \\
\text { institutions from pharmacies }\end{array}$ \\
\hline Norwegian Patient Registry & 2007 & Special health service/Secondary health care: somatic and psychiatric \\
\hline Social Security Database & 1992 (nationwide) & $\begin{array}{l}\text { Pensions/sickness benefits/unemployment insurance/social insurance/disability } \\
\text { insurance }\end{array}$ \\
\hline National Education Database & 1970 & Primary school through university. Results and direction \\
\hline Employment/Income & $1983 / 1993$ & Place/type of work/position/hours \\
\hline $\begin{array}{l}\text { Norwegian Cardiovascular Disease } \\
\text { Registry }\end{array}$ & 2012 & Diseases of the heart and blood vessels \\
\hline Municipal Patient and User Registry & 2016 & $\begin{array}{l}\text { General practitioners, emergency care and dental care. Coming: information on } \\
\text { diverse municipal health and care services, at home/institutions }\end{array}$ \\
\hline
\end{tabular}

Note: More information about the health registries can be found at https://www.fhi.no/en/more/access-to-data/about-the-national-health-registries2/

residency in Norway. Through this PID, it is possible to link information on twins participating in the NTR to information from other registries containing data on health and health-related measures such as prescription drug use and exposures. Table 3 presents an overview of the main nationwide registries that are often used for obtaining such linked data. New legislation, effective from 2018, now permits incorporation into the NTR information from these registries, conditional on twins' consent. For example, the NTR can now include cancer diagnoses from the National Cancer Register within its database if the twin has provided consent. This provides access to high quality and comprehensive health data and greatly reduces the cost and time involved in collecting data for new studies. An overview and additional information about the national health registries can be found at https:// www.fhi.no/en/more/access-to-data/about-the-national-healthregistries $2 /$.

\section{Areas of Research}

NTR as such has no specific research agenda. The role of the NTR is to collect twin data, maintain the registry and facilitate access to data and new data collections for national and international research projects. The Norwegian twin data and the NTR have supported a broad range of research studies, many of which are described in previous overviews (Bergem, 2002; Harris et al., 2002, 2006; Magnus et al., 2016; Nilsen et al., 2013). Scientific publications based on the NTR can be found at the NTR website (https://www.fhi.no/en/more/health-studies/norwegiantwin-registry/). The portfolio of currently ongoing studies utilizes a combination of data sources, often combining questionnaire or interview data with national register linkages. The main focus areas of these studies include disordered personality and substance abuse, social factors and health, psychosocial influences on inflammatory bowel syndrome, a Nordic collaboration on cancer, a follow-up study on Axis I and Axis II psychiatric disorders, research on pain, personality and psychosocial measures, an intervention study of neurocognitive plasticity and training, and a study of societal openness and normative flux based on measures of family demography and social stratification. More information about these studies can be obtained from the NTR (tvilling@fhi.no).

\section{Access to NTR Data}

Norwegian twin data are available for research studies, conditional on twins' consent, compliance with general data protection regulation and obtaining relevant ethics and institutional review board (IRB) approvals. Anonymous data can be shared more freely. Information about the NTR is hosted in English and Norwegian on a website maintained by the NIPH (https://www.fhi.no/en/ more/health-studies/norwegian-twin-registry/). The web portal provides researchers with information about the NTR, descriptions of current research projects, instructions and policies for data access applications, including the fee structure for processing of requests and data. Inquiries can be made to tvilling@fhi.no.

The health data infrastructure landscape in Norway is changing dramatically under the Directorate for eHealth and a national strategy to build an advanced data ecosystem. A main goal is to simplify and secure data access, enable data exploration, analysis and integration across diverse health data resources, such as the health registries and health studies, including the NTR. This new platform is focusing first on the health registries but will eventually provide a centralized and comprehensive overview of the consolidated and structured data that are available across these research resources, including the NTR. This will greatly enhance the research potential of the Norwegian health data and enable researchers interested in using the NTR data to apply for access through a 'one-stop-shop' portal.

Conflicts of interest. None.

Ethical standards. The authors assert that all procedures contributing to this work comply with the ethical standards of the relevant national and institutional committees on human experimentation and with the Helsinki Declaration of 1975 , as revised in 2008 . 


\section{References}

Bergem, A. L. (2002). Norwegian Twin Registers and Norwegian twin studies An overview. Twin Research, 5, 407-414.

Harris, J. R., Magnus, P., \& Tambs, K. (2002). The Norwegian Institute of Public Health Twin Panel: A description of the sample and program of research. Twin Research, 5, 415-423.

Harris, J. R., Magnus, P., \& Tambs, K. (2006). The Norwegian Institute of Public Health twin program of research: An update. Twin Research and Human Genetics, 9, 858-864.

Harris, J. R., Tambs, K., \& Magnus, P. (1995). Sex-specific effects for body mass index in the new Norwegian twin panel. Genetic Epidemiology, 12, 251-265.

Irgens, L. M. (2002). Medical birth registry - An essential resource in perinatal medical research. Tidsskr Nor Laegeforen, 122, 2546-2549.

Kringlen, E. (2016). Twin research in Norway with special emphasis on psychiatric studies. Norwegian Journal of Epidemiology, 26, 5-8.

Magnus, P., Berg, K., \& Nance, W. E. (1983). Predicting zygosity in Norwegian twin pairs born 1915-1960. Clinical Genetics, 24, 103-112.
Magnus, P., Harris, J. R., \& Tambs, K. (2016). Setting up and utilizing Norwegian Twin Panels. Norwegian Journal of Epidemiology, 26, 9-17.

Nilsen, T. S., Brandt, I., Magnus, P., \& Harris, J. R. (2012). The Norwegian Twin Registry. Twin Research and Human Genetics, 15, 775-780.

Nilsen, T. S., Knudsen, G. P., Gervin, K., Brandt, I., Roysamb, E., Tambs, K., ... Harris, J. R. (2013). The Norwegian Twin Registry from a public health perspective: A research update. Twin Research and Human Genetics, 16, 285-295.

Roysamb, E., Nes, R. B., Czajkowski, N. O., \& Vassend, O. (2018). Genetics, personality and wellbeing. A twin study of traits, facets and life satisfaction. Scientific Reports, 8, 12298.

Tambs, K., Harris, J. R., \& Magnus, P. (1995). Sex-specific causal factors and effects of common environment for symptoms of anxiety and depression in twins. Behavior Genetics, 25, 33-44.

Vassend, O., Roysamb, E., \& Nielsen, C. S. (2011). Dental anxiety in relation to neuroticism and pain sensitivity. A twin study. Journal of Anxiety Disorders, $25,302-308$. 